\title{
Surgical Treatment of Hyperparathyroidism Secondary to Chronic Renal Failure: Our Experience with the $7 / 8$ Subtotal Parathyroidectomy Technique
}

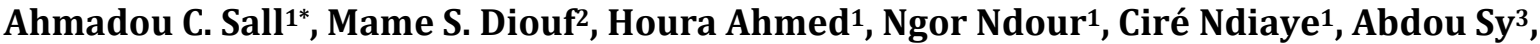 \\ Richard E. A. Deguenonvo², Evelyne S. Diom ${ }^{4}$, Malick Ndiaye ${ }^{3}$, Abdourahmane Tall', \\ Bay K. Diallo ${ }^{5}$, Issa C. Ndiaye ${ }^{1}$, Raymond Diouf ${ }^{2}$
}

${ }^{1}$ ENT Department, Fann National University Hospital, Dakar, Senegal

${ }^{2}$ ENT and Cervico-Facial Surgery General Hospital Idrissa Pouye de Grand-Yoff, Dakar, Sénégal

${ }^{3}$ ENT Department, Diamniadio Children Hospital, Dakar, Senegal

${ }^{4}$ ENT Department, Peace Hospital of Ziguinchor, Ziguinchor, Senegal

${ }^{5}$ ENT Department, Albert Royer Children Hospital, Dakar, Senegal

Email: *sall188@hotmail.com

How to cite this paper: Sall, A.C., Diouf, M.S., Ahmed, H., Ndour, N., Ndiaye, C., Sy, A., Deguenonvo, R.E.A., Diom, E.S., Ndiaye, M., Tall, A., Diallo, B.K., Ndiaye, I.C. and Diouf, R. (2022) Surgical Treatment of Hyperparathyroidism Secondary to Chronic Renal Failure: Our Experience with the 7/8 Subtotal Parathyroidectomy Technique. International Journal of Otolaryngology and Head \& Neck Surgery, 11, 25-30. https://doi.org/10.4236/ijohns.2022.111004

Received: November 10, 2021

Accepted: January 10, 2022

Published: January 13, 2022

Copyright $\odot 2022$ by author(s) and Scientific Research Publishing Inc. This work is licensed under the Creative Commons Attribution International License (CC BY 4.0)

http://creativecommons.org/licenses/by/4.0/ (c) (i) Open Access

\begin{abstract}
Introduction: Surgical management takes place, after a certain period of evolution, on particularly severe forms of secondary hyperparathyroidism, resistant to medical treatment. Subtotal parathyroidectomy is an effective technique in the treatment of these disorders. Method: Our study is retrospective of 33 cases of hyperparathyroidism secondary to chronic renal failure in dialysis patients operated by the $7 / 8$ technique. Identified over a period of 10 years (January 2010 to December 2019), in the ENT department of the Fann University Hospital. Results: Out of 33 cases of secondary hyperparathyroidism, the average age of our patients was 51.24 years with a sex ratio of 0.43 . Causal nephropathy was dominated by nephro-angiosclerosis, which was found in $27.27 \%$ of cases. Bone pain found in 23 patients or $69.69 \%$ was the predominant clinical sign. The average calcemia was $92.7 \mathrm{mg} / \mathrm{l}$. Parathormone was dosed in all our patients and the average was $1611.05 \mathrm{ng} / \mathrm{l}$. The consequences were clinically marked by recurrent paresis in one patient. No case of hematoma or postoperative infection was found. On the biological level 10 patients or $30.30 \%$ had a transient hypocalcaemia. The results were marked by a drop in PTH in 23 patients or $78.78 \%$ of cases. Conclusion: Subtotal parathyroidectomy remains an effective and beneficial therapeutic method for kidney failure patients with secondary hyperparathyroidism.
\end{abstract}




\section{Keywords}

Secondary Hyperparathyroidism, 7/8 Parathyroidectomy, Transient

Hypocalcemia, Persistent Hyperparathyroidism

\section{Introduction}

Secondary hyperparathyroidism (sHPT) is one of the mineral-bone disorders seen in patients with chronic kidney disease (CKD-MBD) [1]. It is characterized by abnormally high levels of parathyroid hormone (PTH) and is associated with an increased risk of cardiovascular morbidity and mortality in dialysis patients [2].

The surgical management intervenes, at the end of a certain period of evolution, on particularly severe forms of secondary hyperparathyroidism, resistant to medical treatment, and aims at a maximum reduction of the parathyroid parenchyma. It is a particularly meticulous and demanding surgery, to be entrusted to a specialized surgeon.

The notion of remaining parenchyma takes on as important a value as that of removed parenchyma. The persistence of stimuli, induced by renal failure, on parathyroid hormone secretion will be the cause of persistence and recurrence after initial surgery.

Surgical management of patients with secondary hyperpathyroidism was centered in the ENT department of the Fann University Hospital.

The objective of this study was to evaluate our experience with the $7 / 8$ technique in the surgical management of hyperparathyroidism secondary to chronic kidney disease and to assess the short- and long-term evolution of this treatment.

\section{Material and Methods}

Our study is a retrospective study of 33 cases of secondary hyperparathyroidism to chronic renal failure in dialysis patients operated for secondary and tertiary hyperparathyroidism by the 7/8 technique which consisted of excision of the 3 parathyroids and half of the fourth gland which seemed to be the most normal. Surgical exploration of the parathyroid compartments for hyperplastic or nodular lesions under general anesthesia was performed in all of our patients. It allowed the localization of the 4 parathyroids in their compartments in all our patients and this allowed the possibility of the realization of the 7/8 technique. It was conducted over a period of 10 years (January 2010 to December 2019) in the ENT department of the Fann University Hospital. We studied the following parameters: Age, gender, etiology of renal failure, length of time on dialysis, clinical signs, biological data, imaging, surgical procedure as well as evolutionary modalities.

\section{Results}

This study included 23 women for 10 men, i.e. a sex ratio of 0.43 (Figure 1). The mean age of our patients was 51.24 years (Figure 2). The causal nephropathy 
was dominated by nephro-angiosclerosis which was found in 9 patients, i.e. $27.27 \%$ of cases. Clinical symptoms were dominated by bone pain found in 23 patients (69.69\%) followed by muscular signs found in $27.27 \%$ (09 patients). The average calcemia was equal to $92.7 \mathrm{mg} / \mathrm{l}$ with extremes of 64 and $131 \mathrm{mg} / \mathrm{l}$. Four patients had hypercalcemia (12.12\% of cases). Parathyroid hormone was measured in all our patients and the average was $1611.05 \mathrm{ng} / \mathrm{l}$ with extremes of 431 $\mathrm{ng} / \mathrm{l}$ and $5000 \mathrm{ng} / \mathrm{l}$ (Figure 3). Cervical ultrasound was performed in all our patients $(100 \%)$ and found parathyroid nodules in $69.69 \%$ of cases (23 patients). Thyroid scintigraphy was performed in 2 patients and was in favor of a right inferior parathyroid hypertrophy in one of the patients and normal in the other case.

A subtotal parathyroidectomy of $7 / 8^{\text {th }}$ was performed in all our patients. The consequences were clinically marked by recurrent paresia in a patient. Biologically 10 patients or $30.30 \%$ had transient hypocalcemia. PTH was dosed in all

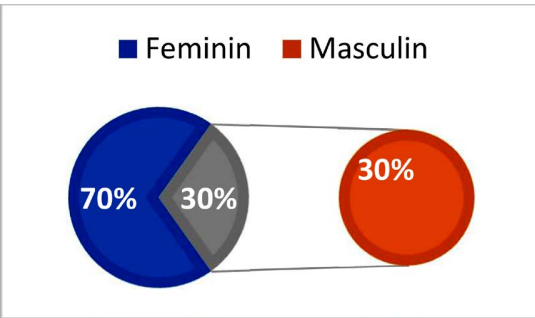

Figure 1. Sex distribution of patients who underwent 7/8 PTX.

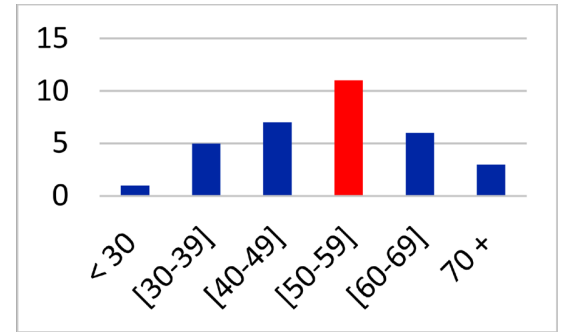

Figure 2. Age (in years) distribution of patients having undergone 7/8 PTX.

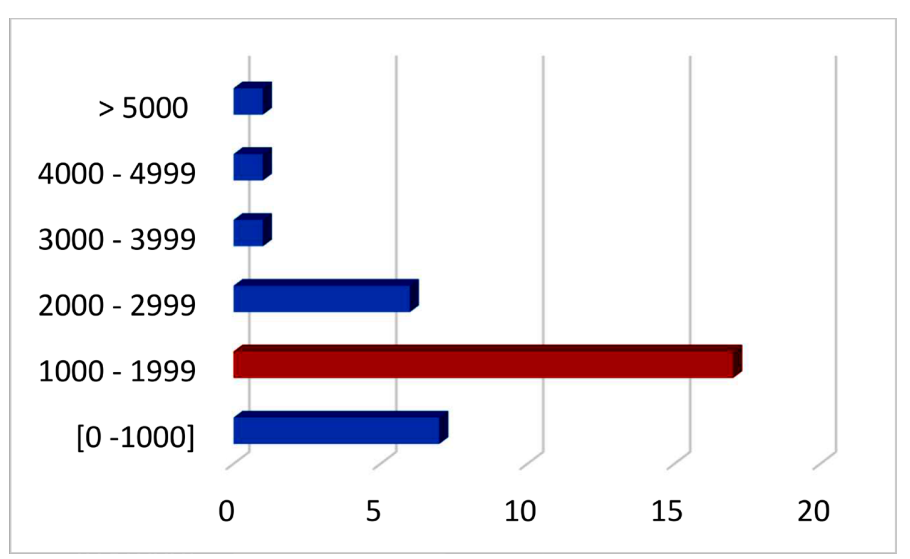

Figure 3. Distribution according to the level of PTHi (ng/l) of the patients having undergone a PTX of $7 / 8$. 
post-op patients, values had dropped by $78.78 \%$ and a persistence of hyperparathyroidism was found in 7 patients or $21.21 \%$.

Parathyroid hyperplasia was the predominant histological type (23 patients)

\section{Discussion}

Hyperparathyroidism, which represents one of the aspects of mineral-bone disorders secondary to chronic renal disease, is a frequent long-term complication observed in chronic renal failure.

Parathyroidectomy is a recognized and effective therapy for the treatment of severe hyperparathyroidism when the indications are well defined.

Several types of procedures can be performed. Complete exploration of the thyroid gland with the discovery of all four parathyroid glands is the rule.

The diagnosis of HPTS is made during the follow-up of patients with chronic kidney disease at the dialysis stage. However, the clinical signs are observed in cases of frank hyperparathyroidism and are preceded by biological and radiological abnormalities [3].

Systematic evaluation of the size of the parathyroid gland helps to choose the treatment of secondary hyperparathyroidism in chronic dialysis patients. The indication for parathyroid surgery can be determined by the number of parathyroid glands with nodular hyperplasia, the location of the glands, the existence of ectopic glands, the prognosis, compliance and general condition of the patient, as well as the availability of an experienced surgeon [4]. Clinical indications for parathyroidectomy are severe hyperparathyroidism (PTH 1000 pg/mL) resistant to medical treatment in the presence of hypercalcemia, bone pain and severe hyperparathyroid bone disease, metastatic calcifications, intractable pruritus or symptomatic myopathy in an unexplained way.

The enlarged parathyroid glands detected by ultrasound (glandular weight greater than $500 \mathrm{mg}$ ) are very frequently nodular hyperplastic glands and hyperparathyroidism may be refractory to medical treatment [5].

In our study, the indication was given to all patients with biological hyperparathyroidism or in the presence of severe symptoms related to hyperparathyroidism and/or in the presence of nodules or hyperplasia of the parathyroid tissues, but also in the intraoperative discovery of four parathyroid glands in a patient with chronic renal failure on dialysis.

The reduction of the parathyroid parenchyma required must be sufficient to avoid its recurrence, and without being too deleterious, in order to avoid prolonged hypocalcemia and permanent hypoparathyroidism [6].

Thus, exploration of the 4 parathyroid sites appears essential for the initial surgical strategy. The $7 / 8^{\text {th }}$ PTX shows efficacy in terms of survival without reoperation and postoperative PTH goals and control, possibly at the expense of calcium homeostasis. Veyrat demonstrated a significant decrease in PTHi levels of approximately $86 \%$ for the $7 / 8^{\text {th }}$ parathyroidectomy group of patients [7].

For Song Kim [8] this procedure is more advantageous because it has a lower 
rate of hypoparathyroidism compared to total parathyroidectomy alone, and is considered a better choice for patients waiting for a kidney transplant. Subtotal parathyroidectomy may also be the preferred approach in predialysis patients, as it results in less postoperative transient hypoparathyroidism, thus causing less deterioration of kidney function than with total parathyroidectomy.

In the literature, studies comparing the post-operative PTH level between a group of patients who underwent $3 / 4$ parathyroidectomy and a group who underwent $7 / 8^{\text {th }}$ parathyroidectomy concluded that a $3 / 4$ parathyroidectomy in HPT2 achieves a PTH level higher than a $7 / 8^{\text {th }}$ PTX, avoiding the occurrence of hypoparathyroidism with its risk of adynamic bone and excess mortality in Perié's study [9].

In our study one patient (3.03\%) presented with recurrent paresis. In the literature, the overall risk of occurrence of a recurrent lesion is estimated between 1 and 5\% [10]. The occurrence of hypocalcemia after parathyroid surgery is variable in the literature. In our study, transient hypocalcemia was found in $30.30 \%$ of the cases corrected by oral or parenteral calcium supplementation.

Studies have shown that despite careful cervical exploration and subtotal parathyroidectomy, persistent or recurrent hyperparathyroidism cannot be avoided in a number of cases [11]. For Arcerio [12], the persistence of hyperparathyroidism corresponds, in most cases, to a failure of the initial surgery to reduce the parathyroid parenchyma, because of the difficulties caused by the topographical variations.

The rate of reintervention ranges from 2.5 to $14 \%$ after subtotal parathyroidectomy. We obtained in our study a decrease in PTHi in $78.78 \%$ of cases and a persistence or recurrence of hyperparathyroidism was noted in 7 of our patients (21.21\%). According to some authors [13] [14] [15], over large retrospective series, the rate of definitive hypoparathyroidism varies between 2 and $17 \%$ after subtotal PTX, over a heterogeneous follow-up period of 18 to 58 months. No cases of hypoparathyroidism have been found in our series.

\section{Conclusion}

Complete exploration of the thyroid gland with discovery of the four parathyroid glands is the rule. The parathyroidectomy of the 7/8 remains the technique of choice to be developed in similarity with the new techniques which are the intraoperative dosage of the PTH and the extemporaneous anatomopathological examination.

\section{Conflicts of Interest}

The authors declare no conflicts of interest regarding the publication of this paper.

\section{References}

[1] Moe, S.M. and Drüeke, T.B. (2003) Management of Secondary Hyperparathyroidism: The Importance and the Challenge of Controlling Parathyroid Hormone Levels without Elevating Calcium, Phosphorus, and Calcium-Phosphorus Product. Amer 
ican Journal of Nephrology, 23, 369-379. https://doi.org/10.1159/000073945

[2] Block, G.A., Klassen, P.S., Lazarus, J.M., et al. (2004) Mineral Metabolism, Mortality, and Morbidity in Maintenance Hemodialysis. Journal of the American Society of Nephrology, 15, 2208-2218. https://doi.org/10.1097/01.ASN.0000133041.27682.A2

[3] Hamouda, M., Ben Dhia, N., Aloui, S., et al. (2011) Traitement chirurgical de l'hyperparathyroïdie secondaire chez l'insuffisant rénal chronique. Néphrologie \& Thérapeutique, 7, 105-110. https://doi.org/10.1016/j.nephro.2010.10.003

[4] Fukagawa, M. and Nakanishi, S. (2003) Role of Parathyroid Intervention in the Management of Secondary Hyperparathyroidism. Nephrology Dialysis Transplantation, 18, 23-26. https://doi.org/10.1093/ndt/gfg1006

[5] De Francisco, A.L.M., Fernandez-Fresnedo, G., Rodrigo, E., et al. (2002) Parathyroidectomy in Dialysis Patients. Kidney International, 63, 161-166. https://doi.org/10.1046/j.1523-1755.61.s80.27.x

[6] Triponez, F., Kebebew, E., Dosseh, D., et al. (2006) Less-than-Subtotal Parathyroidectomy Increases the Risk of Persistent/Recurrent Hyperparathyroidism after Parathyroidectomy in Tertiary Hyperparathyroidism after Renal Transplantation. Surgery, 140, 990-999. https://doi.org/10.1016/j.surg.2006.06.039

[7] Veyrat, M., Fessi, H., Haymann, J.P., et al. (2019) Parathyrö̈dectomie conservatrice des trois quarts, versus parathyroïdectomie subtotale des $7 / 8 \mathrm{e}$, dans l'hyperparathyroïdie secondaire. Annales françaises doto-rhino-laryngologie et de pathologie cervico-faciale, 136, 63-69. https://doi.org/10.1016/j.aforl.2018.01.009

[8] Kim, M.S., Kim, G.H., Lee, C.H., et al. (2020) Résultats chirurgicaux de parathyroïdectomie subtotale pour hyperparathyroïdie rénale. Clinical and Experimental Otorhinolaryngology, 13, 173-178.

[9] Périé, S., Veyrat, M., Haymann, J.P., et al. (2014) Intérêt des parathyroïdectomies des $3 / 4$, sélectives, versus parathyroïdectomies subtotales des 7/8e dans l'hyperparathyroïdie secondaire. Néphrologie \& Thérapeutique, 10, 291-330. https://doi.org/10.1016/j.nephro.2014.07.058

[10] Bratucu, M.N., Garofil, N.D., Radu, P.A., et al. (2015) Surgical Attitude in Patients with Secondary Hyperparathyroidism Undergoing Dialysis. Chirurgia (Bucur), 110, 418-424.

[11] Udelsman, R. (2002) Six Hundred and Fifty Six Consecutive Explorations for Primary Hyperparathyroidism. Annals of Surgery, 235, 665-672.

https://doi.org/10.1097/00000658-200205000-00008

[12] Arciero, C.A., Poeples, G.E., Stojadinovic, A., et al. (2004) The Utility of a Rapid Parathyroid Assay for Uniglandular, Multiglandular, and Recurrent Parathyroid Disease. The American Surgeon, 70, 588-592.

[13] Lorenz, K., Bartsch, D.K., Sancho, J.J., et al. (2015) Surgical Management of Secondary Hyperparathyroidism in Chronic Kidney Disease-A Consensus Report of the European Society of Endocrine Surgeons. Langenbeck's Archives of Surgery, 400, 907-927. https://doi.org/10.1007/s00423-015-1344-5

[14] Schneider, R., Slater, E.P., Karakas, E., et al. (2012) Initial Parathyroid Surgery in 606 Patients with Renal Hyperparathyroidism. World Journal of Surgery, 36, 318-326. https://doi.org/10.1007/s00268-011-1392-0

[15] Tominaga, Y., Uchida, K., Haba, T., et al. (2001) More than 1,000 Cases of Total Parathyroidectomy with Forearm Autograft for Renal Hyperparathyroidism. American Journal of Kidney Diseases, 38, S168-S171. https://doi.org/10.1053/ajkd.2001.27432 